\title{
Nietzsche y Heidegger, una reflexión sobre los alimentos genéticamente modificados
}

\author{
Rebeca Maldonado \\ El ser es el éter en el cual el hombre respira, un éter sin \\ el cual él degenera en mero animal, y toda su acción \\ en mera cría de animales.
}

M. Heidegger

Todo el mundo se vanagloria de que hoy en día "la ciencia comience a dominar sobre la vida". Puede que se llegue a esto, pero lo cierto es que una vida determinada de tal manera no posee ningún valor, porque es mucho menos vida y garantiza mucho menos vida para el futuro que la antigua vida dominada no por la ciencia, sino por instintos y poderosas imágenes llenas de ilusión.

F. Nietzsche

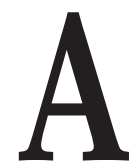

través de la línea de pensar que inicia con el romanticismo, atraviesa a Nietzsche y llega a Heidegger, quiero acercarme a un evento que guarda importantes repercusiones sociales, políticas, económicas, pero también pleno de inquietantes consecuencias filosóficas, me refiero a la aparición de los alimentos transgénicos o alimentos modificados genéticamente. Este modo de acercamiento a temas que aparentemente están fuera de toda relación con la historia de la filosofía es fundamental, ya que permite no sólo interpretar nuestra existencia en la historia, sino además que la filosofía se reinterprete a sí misma. Como veremos, la técnica recibe una interpretación negativa dentro de aquella línea de pensamiento, sin embargo, tiene mucho qué decir y es necesario escucharla, para poder transvalorar la constitución técnica del mundo de la vida guiada exclusivamente por la vorágine del mercado y sus leyes.

La tesis heideggeriana que definitivamente me parece productiva para iniciar esta reflexión, y que a mi juicio resume la postura de Heidegger no sólo con 
respecto a la técnica, sino con respecto a nuestro tiempo, es que la técnica tiene como fundamento de su constitución la reducción del mundo a la representación del sujeto. ${ }^{1}$ Esto significa que para Heidegger la constitución técnica del mundo de la vida no es un fenómeno más a investigar. El problema de la ciencia y de la técnica es un problema señalado, por expresar la entraña metafísica de esta forma de conducirse el Dasein con respecto al ente. Es a partir de la subjetividad que en la modernidad toda región del ente se provoca, se ordena, se dispone, en suma, se vuelve calculable. Los transgénicos u organismos modificados genéticamente son un signo de nuestra época (y de nuestro tiempo); el extremo de esa voluntad que impone en el mundo su marca hasta el extremo de modificar las condiciones mismas de la vida, esto es, su estructura genética.

Contra todo humanismo, la postura de Heidegger es ontológica. Pues es la postura que concede la libertad al hombre en detrimento de la libertad del ser, la que lo ha sacrificado y reducido a una subjetividad a la cual le pertenece exclusivamente la libertad y con ésta el distrito entero del ente. ${ }^{2}$ Por esta razón, si Heidegger encuentra en Schelling un filósofo de quien hay que recuperar puntos de reflexión para nuestra época, es por haber convertido a la libertad, en contra del mecanicismo, en determinación del ser en general, al expresar: "en última y más alta instancia no hay otro 'Ser' que querer. Querer es ser originario. El ser originario es querer". ${ }^{3}$ Para Schelling, no existe oposición entre naturaleza y espíritu, objeto y sujeto, pues como comenta Heidegger, "la libertad misma es una determinación del Ser en general propiamente dicho, que sobrepasa todo ser humano [...] La libertad no es propiedad del hombre, sino el hombre es propiedad de la libertad". ${ }^{4}$ Desde el romanticismo pesa una sospecha en torno a la ciencia, un cuestionamiento sobre su fundamento. Por ello, Schelling observa que si la ciencia busca conquistar la natura-

${ }^{1} \mathrm{Cf}$. Martin Heidegger, "La pregunta por la técnica", en Conferencias y artículos. Barcelona, Ediciones del Serbal, 1994.

${ }^{2}$ En la historia de la filosofia, Schelling ha sido piedra fundamental en la elaboración de una idea de naturaleza que escape al mecanicismo, esto es, a la idea de la naturaleza como un conjunto de engranajes y correas que pueden cambiarse sin que se altere el conjunto. De manera que toda la realidad natural posee una estructura comparable a la de una máquina. Otra característica del mecanicismo es que todo movimiento se efectúa según una rigurosa ley causal, por lo tanto, el mecanicismo es antifinalista. Por ello dirá Schelling, "existe una firme creencia: el pensamiento de la total subjetividad de todo pensamiento y conocimiento, y el de la falta de razón y conocimiento de la naturaleza, junto al modo de representación mecánica que reina en todas partes" (F. W. J. Schelling, Investigaciones filosóficas sobre la esencia de la libertad humana y los objetos con ella relacionados. Madrid, Anthropos, 1989, p. 103).

${ }^{3}$ F. W. J. Schelling, op. cit., p. 147.

${ }^{4}$ M. Heidegger, Schelling y la libertad humana. Caracas, Monte Ávila, 1971, p. 11. 
leza, lo hace bajo el supuesto de que la naturaleza no tiene un fundamento viviente. ${ }^{5}$ Sólo por eso es posible, lejos de la atmósfera del ser, lejos de aquello que otorga vida a la reflexión, que lo vivo también degenere en mero objeto no sólo de análisis o vivisección, sino además en objeto de manipulación.

Frente al pensamiento analítico, la filosofía y su poder sintético, considerará que la ciencia y la técnica degeneran ahí donde no reciben orientación de la atmósfera del ser, como en Heidegger, ahí donde no se realiza desde la óptica de la vida, como en Nietzsche, ahí donde han perdido el horizonte de sentido, convirtiéndose de antemano en una teoría y una praxis que no tienen sentido de futuro. La exclusión de la esfera del sentido es la propia exclusión del espíritu. Por ello es que nos dice Manfred Frank que en el idealismo la razón es la facultad de las ideas, algo que se rige de acuerdo a fines últimos, y, por lo tanto, los procesos que ocurren en ella están al servicio de determinaciones finales, al servicio de fines y sentidos que aunque nunca alcancen realidad o no se puedan comprobar teóricamente ni exista nada en la realidad que les corresponda, tienen validez. ${ }^{6}$ Una ciencia ajena al mundo de los fines y de la esfera del sentido, efectivamente produce, pero ese criterio de lo útil, de lo económico, de lo meramente factible, que se fija en la producción y sólo en la producción, y no en los fines legítimos, convierte a la postre al ser del hombre también en un contrasentido. ${ }^{7}$

${ }^{5}$ Cf. M. Heidegger, op. cit., p. 125.

${ }^{6} \mathrm{Cf}$. Manfred Frank, "Quinta lección", en El dios venidero. Barcelona, Ediciones del Serbal, 1994. (Colección Delos)

7 Sin embargo sería injusto pensar que todos los gobiernos y sociedades son insensibles a la necesidad de reglamentar los alimentos transgénicos. The Royal Society of Canada pide controles más estrictos para los alimentos modificados genéticamente, bajo el argumento de que los cultivos de transgénicos no son equivalentes a los cultivos ordinarios. Y las nuevas tecnologías no deben considerarse seguras a menos que prueben que lo son sobre bases científicas. Pues en términos científicos rigurosos los transgénicos constituyen un daño potencial. Esto es, para una ciencia responsable los partidarios de los transgénicos deben de mostrar un amplio rango de pruebas que demuestre que no traen consigo riesgos inaceptables. Los mejores métodos científicos deben de reducir la incertidumbre en torno a riesgos a la salud, al ecosistema y a la biodiversidad. Se propone además que los organismos encargados de la regulación de la actividad científica deben ser más transparentes en torno a la ciencia y mantener una posición neutral en sus juicios públicos en torno a los riesgos de la biotecnología y revisar los problemas relacionados el aumento del dominio de la empresa privada y lo intereses comerciales en la investigación pública ("Call for Tighter Controls on Transgenic Foods", en Nature, 409, 745-964, 15 de febrero, 2001, p. 749). Mientras tanto, las regulaciones de los países frente a los transgénicos parecen tener un lema: "los cultivos transgénicos son seguros hasta que no se demuestre lo contrario" (Michelle Marvier, "Ecology of Transgenic Crops", en American Scientists, núm. 89, marzo-abril, 2001, p. 167). 
El Systemmprogrammm, texto atribuido a Schelling, ${ }^{8}$ frente a una fundamentación mecanicista-causal, se propone una fundamentación a partir de la idea, esto es, por medio de fines. ${ }^{9}$ A mi juicio, falta una ciencia y una técnica desde la óptica de la vida y del ser. Pues una ciencia que justamente al tener como principio y fin de su actividad, el logro de cierto objetivo en particular, muy particular, a la larga pulverizará la vida en su conjunto. La ciencia necesita un proyecto y un sentido amplios que le otorgue sentido, que no es la justificación del apoderamiento de las condiciones de la vida como "el proyecto esencial - escribe Heidegger- del estar en movimiento de la vida". ${ }^{10}$ Los transgénicos no están dentro de ese movimiento esencial de la vida, así se llama al gen extraño que se introduce en el genoma de la planta receptora "gen antisentido"; dicho gen al inhibir la síntesis de enzimas, convierte la vida en error, las condiciones de la vida en aberración, el instinto de la vida en antisentido. ${ }^{11}$ Es en los transgénicos, como caso particular del proceder científico, donde palmariamente vemos la manifestación de las principales críticas que construyeron Nietzsche y Heidegger a la ciencia.

${ }^{8}$ Siguiendo la versión de Manfred Frank, sabemos que el origen del escrito es discutible, sin embargo Horst Fuhrsman el editor de las cartas de Schelling, cuenta una historia a ojos del autor de $E l$ dios venidero plausible: Probablemente Schelling le entregó el escrito a su amigo Hölderlin a su paso por Fráncfort, cuando viajaba hacia Leipzig en abril de 1796. Schelling ya le había informado de ciertos futuros proyectos a Hegel en ese enero de 1796 en una carta: "Aquí en esta tierra nuestra de curas y escribanos, todo se me hace demasiado estrecho. iQué feliz me sentiré cuando pueda respirar aires más libres! Sólo entonces podré meditar sobre planes de largo alcance, cuando pueda llevarlos a cabo, y estoy seguro, amigo mío, de que puedo contar contigo para esta empresa" (apud M. Frank, op. cit., p. 157).

9 Dice Schelling, “¿Cómo tiene que estar constituido un mundo para una esencia moral? Quisiera dar otra vez alas a nuestra física, que avanza fatigosamente de experimento en experimento". Posteriormente señala: "Sólo lo que es objeto de la libertad se llama idea" (F. Hölderlin, "Proyecto", en Ensayos. Madrid, Ediciones Hiperión, 1990, p. 27).

${ }^{10}$ M. Heidegger, Schelling y la libertad humana, p. 169.

${ }^{11}$ Cabe agregar que la ingeniería genética transfiere genes de cualquier especie -animal, bacteria, planta o virus- a cualquier otra especie, sin importar lo poco relacionadas que esas especies puedan estar entre sí. De esta manera, se transfiere el gen de la medusa a plantas para que aparezcan más luminosas. Este tipo de casos, refrendan nuestra hipótesis de que la ingeniería genética transforma la vida en antisentido y, que fuera del propio movimiento de la vida, "estas revolucionarias técnicas moleculares permiten a los científicos enteramente generar organismos con una nueva combinación de propiedades" (M. Marvier, "Ecology of transgenic Crops", en op. cit., pp. 160). 
Nietzsche reflexionó sobre las consecuencias del surgimiento de la figura del científico, sobre ese sujeto que, yendo más allá de sí mismo, contra sí mismo, se pone en contra de la vida al afirmar en Las ventajas y desventajas de los estudios históricos para la vida, que si la ciencia tiene un lema es: la verdad aunque perezca la vida. ${ }^{12}$ En el caso de los alimentos transgénicos, esta aseveración de Nietzsche resulta iluminadora. Pues, en efecto, mediante la biotecnología es posible modificar el genoma de una planta para que resista la madurez, para que resista condiciones ambientales agresivas, como heladas, sequías, suelos salinos, para que resista plagas de insectos y enfermedades. En el caso del maíz transgénico, al introducir en el genoma de una planta el gen que codifica la resistencia a insectos, hace que se reduzca su población, afectando con ello a aves y a murciélagos, al ser los insectos las presas de dichos animales. ${ }^{13}$ Desde una interpretación nietzscheana se trataría de poner la vida contra la vida, de que la vida resista a la vida. Desde una perspectiva heideggeriana, estamos ante la manipulación misma de la vida, de las condiciones mismas de la vida, en aras de una subjetividad que vuelve el espacio natural conforme, adecuado, exactamente a la medida de las necesidades de los hombres, de una subjetividad que controla, manipula, pervierte, altera la naturaleza en aras no sólo de una racionalidad, sino del propio placer, de las propias necesidades humanas y del consumo. Enfermando, debilitando, castrando, manipulando la vida; modificando la dirección misma de la vida, sus códigos genéticos, de esa manera el científico se apodera de la vida, se pone contra ella. Y, en este sentido, veríamos hoy en la manipulación genética el triunfo completo de la racionalidad en el dominio de la naturaleza y del hombre, esto es: nihilismo. ${ }^{14}$

${ }^{12} \mathrm{~F}$. Nietzsche, Sobre la utilidad y el perjuicio de la historia para la vida. Madrid, Biblioteca Nueva, 1999, p. 68.

${ }^{13}$ Con el afán de no hacer uso de pesticidas se puede introducir en la planta del maíz un gen de una bacteria llamada Bacillus thuringiensis, el cual produce un componente insecticida llamado toxina Bt. John Losey y sus colegas de la Universidad de Cornell encontraron que el 56\% de las larvas de las mariposas monarcas sobrevivieron al alimentarse del polen de plantaciones de maíz transgénico, mientras que el 100\% de las larvas de las mariposas monarcas alimentadas con maíz no transgénico sobrevivieron. Cabe agregar que el polen de los cultivos de maíz transgénico puede desplazarse por efecto del viento hasta $60 \mathrm{~m}$ y cubrir la superficie de las plantas vecinas, y por lo tanto afecta directamente no sólo a los insectos contra los cuales está destinado. Es por esta razón que afecta a la larva de la mariposa monarca e incluso a insectos favorables a la agricultura (Cf. M. Marvier, "Ecology of Transgenic Crops", p. 163).

14 "Este volverse consciente de sí mismo -escribe Nietzsche- justo este tomar conciencia es la hybris y la impiedad de nuestro ser moderno. Todo nuestro ser moderno, en cuanto no es debilidad, sino poder y conciencia de poder, se presenta 
Sin embargo, por ser Nietzsche un filósofo de la Tierra y de la vida, por ser un filósofo que constantemente pregunta por la vida y por el tipo de vida que genera tal o cual tipo de moral, tal o cual tipo de hombre, su postura es fértil para establecer una distinción entre una ciencia que castra la vida y otra que se hace desde la óptica de la vida. En un afán de pensar el origen del debilitamiento y de la enfermedad de la conciencia moderna, como el hecho histórico fundamental y determinante, en La genealogía de la moral, si bien Nietzsche observa en la religión la fuente del nihilismo, también hace de la ciencia sucedánea de la religión. La ciencia, como la técnica, también está dominada por el ideal ascético, por el apoderamiento y el debilitamiento de la Tierra y de la vida, pues como en la religión, diría Nietzsche: "domina un resentimiento sin igual, el resentimiento de un insaciado instinto y voluntad de poder que quisiera enseñorearse, no de algo existente en la vida, sino de la vida misma, de sus más hondas, fuertes, radicales condiciones". Y agrega: "en ella se hace un intento de emplear la fuerza para cegar las fuentes de las fuerzas; [...] se vuelve incluso más segura de sí y más triunfante a medida que disminuye su propio presupuesto, la vitalidad fisiológica". ${ }^{15}$ Como el ideal ascético en la religión, para Nietzsche, es posible pensar que, en el fondo, lo que modula a la actividad científica no es el apego a la vida, sino la autodestrucción, la autonegación y el autosacrificio. Y los presupuestos de ese apoderamiento de la vida, es el debilitamiento de los instintos. Es la vida enferma, la que enferma la vida. Como el sacerdote, el científico "sólo el sufrimiento mismo, el displacer de quien sufre, es lo que él combate, pero no su causa, no el auténtico estar enfermo -esto tiene que constituir nuestra máxima objeción de principio contra la medicación sacerdotal". ${ }^{16}$ Nosotros diríamos contra la medicación científica. Podemos hablar entonces de una ciencia y de una técnica desde la óptica de la vida como aquella que combate las causas de la enfermedad, del deterioro y la decadencia del hombre y la Tierra, y otra, que genera mayor enfermedad y decadencia, que perpetúa la destrucción y el debilitamiento.

Más aún, cuando los alimentos transgénicos manifiestan un control sobre las formas en las que hasta ahora la vida se ha expresado, no mediante una selección de tipos que al campesino, a lo largo de generaciones, le permiten ir mejorando sus productos y sus cosechas, sino al introducirse en el genoma

como pura hybris e impiedad. Hybris es hoy toda nuestra actitud con respecto a la naturaleza, nuestra violentación de la misma con ayuda de las máquinas y de la tan irreflexiva inventiva de los técnicos e ingenieros" (F. Nietzsche, La genealogía de la moral. Madrid, Alianza, 1981, p. 131). Esta desmesura en el dominio entero del ente por parte de la subjetividad o de la conciencia, para Nietzsche, es nihilismo.

${ }^{15}$ F. Nietzsche, La genealogía de la moral, p. 137.

${ }^{16}$ Ibid., p. 151. 
de una planta una dirección, un sentido que a la postre amenaza la existencia de la biodiversidad, de la salud humana y animal. Los transgénicos enuncian un caso de nihilismo, ausencia total de ser, de sentido y de valor, al ser producto de una ciencia que incluso ha diseñado genéticamente semillas estériles, esto es, semillas que tienen candados genéticos para que no puedan ser utilizadas de nuevo, y de esta manera, introducir incluso a la vida misma en la lógica del mercado, al destinar a los campesinos a ser eternamente compradores de semillas. La industria de los transgénicos abre la posibilidad no sólo de manipular la vida, sino de que existan propietarios de la vida y de las condiciones de la vida. En este sentido, Heidegger observó que "la ciencia dispone de lo ente cuando consigue calcularlo por adelantado en su futuro transcurso". ${ }^{17}$ Podemos decir ahora que aquella brega de Schelling por lograr una nueva comprensión de la naturaleza ajena al mecanicismo, ha caído en el olvido. Peor aún, que dentro de una comprensión mecanicista, la comprensión que actualmente se tiene de la naturaleza es un mero espacio de cálculo y de dominio sin precedentes. Y, sin embargo, si hoy los cultivos transgénicos están en entredicho es porque sus daños y sus riesgos resultan incalculables.

\section{III}

Para Heidegger, con la técnica, entendida como Gestell o estructura de emplazamiento, asistimos a una manipulación y provocación de la fuente misma del develamiento, de manera que deja de existir la poiesis entendida como un dejar venir de lo oculto al estado de desocultamiento. ${ }^{18}$ La biotecnología muestra la radicalidad de este dominio de Gestell, en la cual todo se presenta en "el estado de desocultamiento de las existencias". Y dentro de este todo, está el hombre, cuyo sentido o suprema dignidad de su esencia es: "cobijar sobre esta Tierra el estado de desocultamiento, y con él antes que nada, el estado de ocultamiento". ${ }^{19}$ El hombre mismo ahora es provocado por la técnica. Es también conminado y provocado para que extraiga sus fuerzas. Es también un reservorio de energía. Y cuando el hombre como estado de abierto y lugar del desocultamiento cae también dentro de la provocación de la técnica

17 M. Heidegger, "La época de la imagen del mundo", en Caminos de bosque. Madrid, Alianza, 1996, pp. 85-86.

${ }^{18}$ Según Heidegger, "toda acción de ocasionar aquello que, desde lo no presente avanza a presencia es poiesis. pro-ducir, traer-ahí, delante" (M. Heidegger, "La pregunta por la técnica", en op. cit., p. 14.) La ciencia para Heidegger es una estructura de emplazamiento que desfigura la poíesis (Cf. ibid., p. 32).

${ }^{19}$ Ibid. p. 35. 
entonces el peligro es que quede amenazada cualquier nueva posibilidad de develamiento del ser. La condición de este hecho es la conversión del ser del hombre en subjectum.

Según Heidegger, la transformación del mundo en imagen, proceso mediante el cual a la vez que el ente se transforma en objeto y el ser humano en sujeto, es la esencia de la edad moderna. ${ }^{20}$ La figura del científico es expresión de nuestra existencia histórica. Esto es, expresa la conversión del hombre en subjectum. El ser del hombre "se convierte en aquel ente sobre el que se fundamenta todo ente en lo tocante a su modo de ser y su verdad. El hombre se convierte en centro de referencia de lo ente como tal". ${ }^{21}$ Por ello, es posible ver, a través de la lectura heideggeriana de la técnica, en los transgénicos una de las manifestaciones más esenciales y radicales de la edad moderna. Esta creación de la biotecnología de consecuencias impredecibles en la cadena alimenticia llega a "una decisión esencial sobre lo ente en su totalidad". ${ }^{22}$

De la misma manera, para Nietzsche, la aparición del hombre de ciencia es uno de los acontecimientos fundamentales de la modernidad. En La genealogía de la moral advierte del significado que tiene este hecho en la historia moderna.

¿No se encuentra en un indetenible avance a partir de Copérnico, precisamente el autoempequeñecimiento del hombre, su voluntad de autoempequeñecimiento? Ay, ha desaparecido la fe en la dignidad, singularidad, insustituibilidad humanas dentro de la escala jerárquica de los seres -el hombre se ha convertido en un animal sin metáforas [...] A partir de Copérnico el hombre parece haber caído en un plano inclinado - rueda cada vez más rápido, alejándose del punto central-, ¿hacia dónde?, ¿hacia la nada?, ¿hacia el horadante sentimiento de su nada?23

Si en La verdad y la mentira en sentido extramoral, Nietzsche nos había dado una definición del hombre, como un ser productor de metáforas, ocurre posteriormente que, en el momento en que según Nietzsche la ciencia se interpone entre el pensamiento y la vida, el hombre deviene en un animal sin metáforas. La transformación del hombre en un animal sin metáforas en vir-

${ }^{20} C f$. M. Heidegger, "La época de la imagen del mundo", en op. cit.

${ }^{21}$ Ibid., p. 87.

22 Ibid., p. 88.

${ }^{23}$ F. Nietzsche, La genealogía de la moral, p. 178. Es importante agregar que en los fragmentos póstumos casi de manera semejante escribe Nietzsche: "Desde Copérnico ha rodado el hombre desde el centro hasta la periferia" (F. Nietzsche, La voluntad de poderío. Madrid, EDAF, 1981, p. 33). 
tud de la aparición de la ciencia moderna, podemos asemejarla con aquel proceso mediante el cual, según Heidegger, el mundo se transforma en imagen.

Esta violentación de la naturaleza y del ente mismo, basado en un exacto cálculo y determinación del ser y su transcurso, que convierte al hombre, según Nietzsche, en un animal sin metáforas, podemos verlo en ese homúnculo u hombre degradado que en la actualidad nos muestra las ciencias de la vida: un animal reducido a la literalidad de una secuencia completa de instrucciones genéticas, gracias a ese conocimiento demasiado exacto de cómo estamos hechos y de cómo funcionamos, en aras del cálculo, en aras de la planificación y del exacto ordenamiento de todas las cosas. Un animal sin metáforas que no se diferencia, por ejemplo, desde la perspectiva de la ciencia, de la secuenciación genética de la mosca de la fruta, ni de la levadura, excepto por su número de piezas. ${ }^{24}$

Este sujeto, en tanto que subjetum, en tanto animal sin metáforas, que ha puesto frente a sí a una naturaleza, a un mundo, y a sí mismo, impide descubrir y experienciar una relación con el mundo como unidad originaria y originante. ${ }^{25}$ No sin razón, desde el romanticismo, existe un distanciamiento con respecto a esa razón que pone frente a sí al ente sin posibilidad de pertenencia y copertenencia, es ese sujeto que representa, y que es manifestación para nada inofensiva de nuestra época de la imagen del mundo la que para Hölderlin nos ha exiliado del jardín de la naturaleza. ${ }^{26}$ Para el romanticismo la naturaleza era una totalidad, algo orgánico, algo que de faltar alguno de sus miembros, la totalidad desaparece. Y por eso es que la naturaleza era un ideal que debía servir de modelo no sólo al Estado, sino también al arte. Aquella comprensión básica del texto de la naturaleza, como fuente de analogías originarias que dan lugar al mito y a la poesía, en este momento de nuestra historia se destruye. Al perder las referencias más originarias de lo que hasta ahora ha significado la vida, perdemos con ello el hábitat más originario del pensar, del arte y del meditar, a cambio diría Paul Celan

24 "The yeast genome is closer to the human genome than anything completely sequenced so far", dice el doctor Francis Collins, director del National Center for Human Genome Research (NCHGR), parte del National Institutes of Health (NIH). Desde la perspectiva del año de 1996, el ADN de la levadura comparte muchas similitudes con el ADN del ser humano, y encontrar los genes de la levadura volvía más fácil determinar lo que contiene la base del genoma humano. Todas las eucariotas (animales, plantas y hongos), esto es, organismos que tienen una estructura interna compleja, comparten similitudes en su estructura molecular, incluyendo un núcleo distinto y estructuras de compartimientos que dan lugar a procesos especializados.

${ }^{25}$ M. Heidegger, Schelling y la libertad humana, p. 197.

${ }^{26}$ Cf. F. Hölderlin, Hiperión. Madrid, Ediciones Hiperión, 1998. 
Ha llegado la hora:

La hoz del cerebro, lustrosa, vaga en el cielo, circundada por el astro de hiel,

los antimagnéticos, los amos, resuenan. ${ }^{27}$

El hombre, para Nietzsche y Heidegger, languidece gracias a esa "luz demasiado luminosa, demasiado repentina, demasiado oscilante" 28 que arroja la técnica sobre sí y alrededor suyo. Por eso la técnica es el modo extremo de ocultarse del ser. Sin sombras, sin misterio, no hay un hacia donde. Sin ponerse al abrigo en lo oculto no es posible la creación, una nueva escucha, nuevos develamientos. Es por lo oculto que el ser del hombre no se apropia de las condiciones del ser, sino que arraiga en ellas. ${ }^{29}$ Demasiada luz es la que rodea al hombre, cuando justo lo que necesita la vida para ser ese juego entre ocultamiento y desocultamiento, luz y oscuridad, ámbito en el cual según Heidegger la verdad originaria adviene. ${ }^{30}$ Ésta parece ser también la sentencia de Paul Celan

Habla también tú, Habla por último, di tu sentencia.

Habla:

Mas no separes el no del sí.

Dale también a tu sentencia el sentido:

dale sombra

${ }^{27}$ Paul Celan, Antología poética. Trad. de Patricia Gola. Puebla, Universidad Autónoma de Puebla, p. 126.

${ }^{28}$ F. Nietzsche, Sobre la utilidad, p. 100.

${ }^{29}$ Schelling puede decir: "sin esta oscuridad preliminar no hay realidad alguna para la creatura; las tinieblas son su necesario patrimonio [...] no sabríamos de nada que pudiera estimular al hombre a aspirar con todas sus fuerzas hacia la luz, que la conciencia de la noche oscura, de la que surgió elevándose desde allí a la existencia" (F. W. J. Schelling, op. cit., p. 169).

${ }^{30}$ De esta necesidad de las sombras, no sólo como condición del arte sino también de la vida nos habla Nietzsche: "Todo lo vivo -dice Nietzsche- necesita alrededor una atmósfera, una aureola llena de misterio. Si se le retira esta envoltura, si se condena a una religión, a un arte, a un genio, a girar como un astro sin atmósfera, no nos deberíamos sorprender si acontece su petrificación y se seca convirtiéndose en estéril" (F. Nietzsche, De la utilidad..., p. 99). 
Dale sombra suficiente,

dale tanta

cuanta sabes distribuida en torno tuyo entre

la medianoche y el mediodía y la medianoche.

Mira en derredor:

mira cómo cobra vida por doquier.

¡Por la muerte! ¡Lleno de vida!

Verdad habla el que sombras habla.

Mas ahora se encoge el sitio donde estás parado:

¿Ahora, hacia dónde, despojado de sombras, hacia dónde? ${ }^{31}$

${ }^{31}$ P. Celan, Antología poética, p. 61. 